\title{
The Contribution of Waves in Mixing Processes of the Patos Lagoon Plume
}

\author{
Eduardo de Paula Kirinus ${ }^{1 *}$, Wiliam Correa Marques ${ }^{1}$, Julliet Correa da Costa ${ }^{2}$, \\ Elisa Helena Leão Fernandes ${ }^{2}$ \\ ${ }^{1}$ Instituto de Matemática Estatística e Física, Universidade Federal do Rio Grande, Rio Grande do Sul, Brazil \\ ${ }^{2}$ Instituto de Oceanografia, Universidade Federal do Rio Grande, Rio Grande do Sul, Brazil \\ Email: "ekirinus@gmail.com
}

Received July 28, 2012; revised August 29, 2012; accepted September 29, 2012

\begin{abstract}
The analysis of wave effects above salinity is important in order to define mixing processes and their potential to change density gradients, since action in the region of the Patos Lagoon plume is highly dynamic. This paper aims to evaluate the influence of waves on the mixing pattern of the adjacent continental shelf. Constantly marked by tides and circulation variations, changing from flood to ebb tide, salinity stands as a major parameter for analysis. The study is based on hydrodynamic numerical modeling experiments using the TELEMAC3D model and waves generated by the wind using the TOMAWAC coupled model. The comparison between the situations considering the waves generated by the wind and without waves was made through time series analysis, stratification series, transversal cross sections, longitudinal cross sections, salinity mean fields and diagrams by Richardson and Brünt-Väisäläs frequency parameters. With the cross sections analysis, the mixing effect generated by the waves was observed, demonstrating clearly that the waves were capable of raising the superficial salinity in regions far from the Patos Lagoon entrance, while at the entrance, the wave effects enhanced the mixing on the deepest layers, decreasing the saline intrusion and expanding the plume more radially on the surface. The space-temporal diagrams were effective to demonstrate the modulation effect of the waves over the salt mixing of saline waters, revealing that wave effects decrease the stratification as well as the Brünt-Väisäläs frequency and increase the period of buoyancy, due to the mixing increase.
\end{abstract}

Keywords: Vertical Mixing; Tridimensional Numerical Modeling; Stratification

\section{Introduction}

Many physical processes such as salinity gradients, temperature fluctuations and velocity gradients are linked with the vertical mixing [1,2]. Such mixing processes are closely related to the turbulent processes that occur in the adjacent water layers; moreover, they can be generated by the breaking of internal waves or by the instability caused by shearing which occurs between the water layers [3]. Mixing processes are mainly caused by vertical circulation, this, in turn, can be generated by factors such as river discharge, density and/or salinity variations, current speed, tides, winds, and wave action. Each of these forcing acts, according to their spatial and temporal scale of action along with the river discharge play a very important role in the generation of mixing in the Patos Lagoon entrance [1,4]. Analyzing the effects of waves generated by the wind on the salinity parameter is important in order to define the mixing processes and changes in the density gradients, since the region of action in the Pa-

\footnotetext{
${ }^{*}$ Corresponding author.
}

tos Lagoon plume is highly dynamic due to the influence of wind setup, tides and remote effects [4]. The main motivation of this work is the interest in understanding and quantifying the mixing processes in the adjacent coastal zone and the influence of waves generated by the wind in the maintenance of this pattern, mainly, in the region of highest occurrence of plume of the Patos Lagoon [4].

Therefore, the objective of this study is to analyze the interaction between the waves generated by the wind and their alteration on the salinity pattern, verifying thus, its contribution to the coastal processes.

The Patos Lagoon (Figure 1) can propagate its fresh water plume for $50 \mathrm{~km}$ from the entrance of the estuary [5], while Marques, et al. [2] concluded that the influence of the fresh water plume can be propagated $40 \mathrm{~km}$ into the ocean and also $35 \mathrm{~km}$ towards the north. During periods of river discharge above the average with the addition of winds continuously from the north quadrant, the mixing zone can be restricted to the access channel or completely expelled to the adjacent coast, forming 

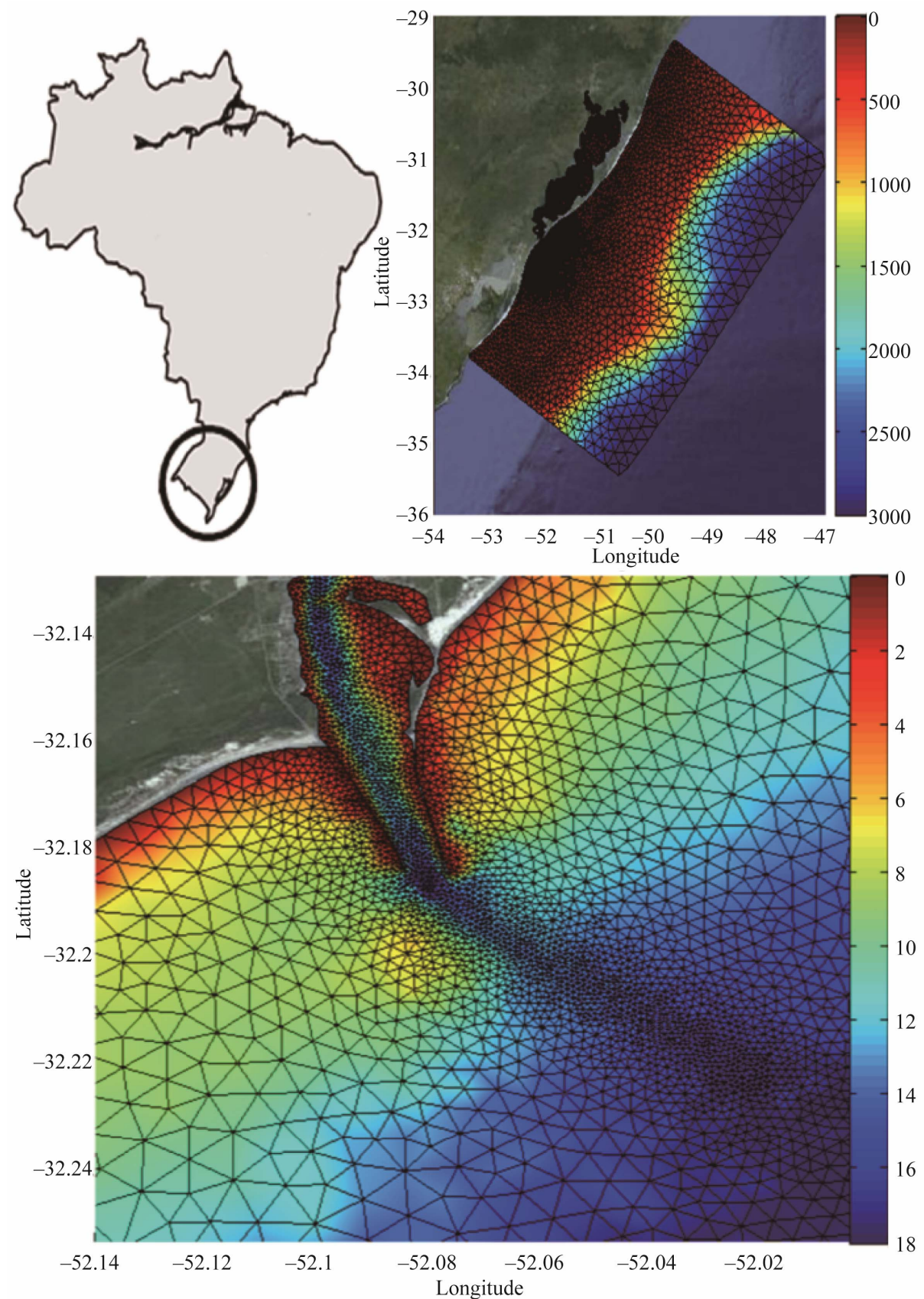

Figure 1. Study site and the simulation grid applied.

less dense plumes of water $([2,4,6])$. The effects of NW and SW winds play an important role in the process of salinization and desalinization of estuarine waters [7], forming vertical structures of salinity ranging between events of saline nature and well mixed [8].

The action of winds favorable to upwelling with high river discharge [9], contributes to the expansion of the plume towards the ocean, increasing the stratification of the water column. Moreover, winds not favorable to upwelling weaken the superficial currents promoting mixing and scattering of the plume, forming subsequently a coastal current ([2-4]).

\section{Methodology}

In this work, the use of three-dimensional hydrodynamic simulations and simulations of the waves are of great importance on account of the difficulties of visualization and interpretation of data in this environment, which has a large temporal and spatial variability of physical characteristics in terms of external factors such as wind and river discharge [10]. 


\subsection{The Numerical Model}

The hydrodynamic simulations were performed with the TELEMAC model. The TELEMAC system of numerical modeling was developed by the Laboratoire National d'Hydraulique of the Company Electricité de France (EDF), and it is based on the finite element methods [11].

This model solves the Navier-Stokes equations for free surface flows accepting the hypothesis of hydrostatic equilibrium, assuming the free surface flow with boundary conditions generated from wind stress. Furthermore, the model considers the free surface evolution as a function of time, and it uses the equations of the advectiondiffusion for the transport of the tracers concentrations (salinity, temperature, or sediments in suspension). These are average approximations that prove to be suitable for applications in shallow water, with vertical velocities smaller than the horizontal. TELEMAC has already been used in the study area to describe the estuarine circulation, morphodynamic processes and sediment dispersion to define the main forces acting in the Patos Lagoon plume, and also to demonstrate the energy potential of the region $[1,2,4,8,10,12]$.

TOMAWAC module was used for simulating the wave field generated by the wind. The numerical model TOMAWAC-TELEMAC-based Operational Model Addressing Wave Action Computation is a spectral model of wave of third generation that calculates the parameters of the waves generated by the wind, shoaling, non-linear interactions, dissipation of energy due to whitecapping, friction background and breaks induced by the wave [13]. This module is part of TELEMAC system, and was used for evaluating the interaction of the waves with hydrodynamics.

Marques, et al. [1,2,4] performed the calibration and validation of hydrodynamic model TELEMAC3D for the Continental Shelf in Southern Brazil. [13] carried out the calibration and validation of wave model TOMAWAC for the same region. Therefore, tests for calibration and validation will not be presented herein, since the same parameters used by these authors were applied into this study (Table 1).

Data were extracted for the region between latitudes $25^{\circ} \mathrm{S}$ and $38^{\circ} \mathrm{S}$ and between longitudes $42^{\circ} \mathrm{W}$ and $52^{\circ} \mathrm{W}$, with a spatial resolution of $111 \mathrm{~km}$ and temporal resolution of 6 hours and the simulations were performed for the period from January 1 to April 25 1998. This year was chosen due to the high river discharges that enhanced the strong ebb flows at the mouth of the Patos Lagoon, generating a large plume with important alterations in the haline patterns of the region [4].

\subsection{Methodology of Analysis}

The quantification of the mixing process can be carried
Table 1. Parameters used in the simulations.

\begin{tabular}{cc}
\hline \multicolumn{1}{c}{ TOMAWAC } \\
\hline Number of Directions & 36 \\
Number of Frequencies & 40 \\
Dissipation Model & Roelvink Model \\
Wind Drag Coefficient & $10^{-3}$ \\
Triad Interactions & 1 \\
Wind Generation Coefficient & 1.8 \\
TELEMAC3D & \\
Coriolis Coefficient & $-7.70 \times 10^{-5} \mathrm{~N} \cdot \mathrm{m}^{-1} \cdot \mathrm{s}^{-1}$ \\
Turbulence Horizontal Model & Smagorinsky \\
Turbulence Vertical Model & Mixing Length $(\mathrm{Jet})$ \\
Scale of Mixture Length & $10 \mathrm{~m}$ \\
Friction Background Law & Manning \\
Influence Wind Coefficient & $6 \times 10^{-6} \mathrm{~N} \cdot \mathrm{m}^{-1} \cdot \mathrm{s}^{-1}$ \\
\hline
\end{tabular}

out through data collection from the saline flows or considering the density gradients generated due to saline alterations in time. According to [14], salinity is the most indicated parameter to study plume fronts because it is able to interact with limiting regions between the fresh and saline waters, as well as it is able to illustrate correctly the influence of river discharges [15]. The salinity mean fields were obtained for the superficial layer, and then a time average was taken from all the simulations with the waves generated by the wind and simulation without the waves (Figure 2).

Thus, the three-dimensional simulation of the TELEMAC system offers the necessary data in order to estimate qualitatively the mixing intensity and the degree of stratification by the dimensionless number of Richardson (Ri) and the Brunt-Väisälä frequency $\left(\mathrm{N}^{2}\right)$, also known as buoyant frequency [16]. These methodologies are widely used for allowing the visualization of the vertical flow structures as vertical variations of density [17].

$$
\begin{aligned}
& \mathrm{Ri}=-\frac{\frac{\mathrm{g}}{\rho} \frac{\partial \rho}{\partial \mathrm{z}}}{\left(\frac{\partial \mathrm{u}}{\partial \mathrm{z}}\right)^{2}} \\
& \mathrm{~N}^{2}=-\frac{\mathrm{g}}{\rho} \frac{\mathrm{d} \rho}{\mathrm{dz}}
\end{aligned}
$$

where: $\mathrm{g}$ is the acceleration of gravity $\left(\mathrm{m}^{2} \cdot \mathrm{s}^{-1}\right), \rho$ is the density $\left(\mathrm{kg} \cdot \mathrm{m}^{-3}\right)$, u is the velocity vector $\left(\mathrm{m} \cdot \mathrm{s}^{-1}\right)$. For the analysis of the Richardson number (Equation (1)), they were considered the gradient of density and velocity gradient in the $\mathrm{x}$ and $\mathrm{y}$ directions. This parameter defines the transition between laminar and turbulent flow, in a stable flow, $\mathrm{Ri}=0.25$. As for the value of $\mathrm{Ri}<0.25$, the turbulence overcomes the density stratification generat- 


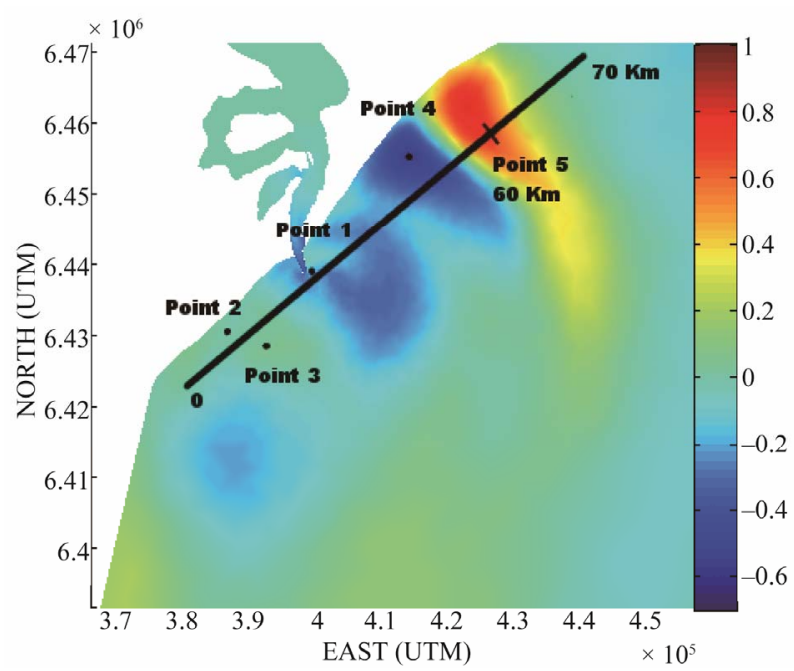

Figure 2. Difference of the salinity mean fields between simulations. Site of the points and salinity profiles with the initial and final distances. Note the location of point 5 , at $60 \mathrm{~km}$ from the beginning of the vertical profile.

ing vertical mixing [18]. The frequency of Brunt-Väisälä (Equation (2)), also known as the Buoyancy Frequency, defines whether the stratification of the water layer is stable or not, it may generate mixing when, $\mathrm{N}^{2}>0$ the stratification is stable, while if $\mathrm{N}^{2}<0$ the stratification is unstable.

According to [19], the maximum of the buoyancy frequency occurs when there is a greater stratification in the water column, as well as the largest disturbances in pycnocline. However, this relationship is inverse when compared with the buoyancy period (given in hours), because the higher the buoyancy frequency, the smaller the buoyancy period, that is, when the mixing processes in the water layer increase, the buoyancy period also increases.

\section{Results and Discussions}

Results of two simulations were used, while one considered the action of waves, the other one did not consider the action of waves generated by the wind. The results were analyzed in a comparative way, to determine the efficiency of the waves in order to promote or not the mixing in the zones of plume influence, surrounding the mouth of the Patos Lagoon. Thus, five points were chosen for the analysis of the results along the coastal zone, in the region of direct influence of the Patos Lagoon plume (Figure 2), being the points 1, 2 and 3 in the south of the mouth of the Patos Lagoon and points 4 and 5 in the north.

In order to analyze this region, temporal series of salinity at the points were taken throughout the simulation, as well as the salinity mean fields and diagrams of temporal and spatial variation for the dimensionless num- ber of Richardson and for the Brunt-Väisälä frequency (Buoyancy Frequency).

From the analysis of the salinity mean fields, with the calculation of the superficial difference (Figure 2) between the salinity mean field with the waves action and the salinity mean field without the influence of the waves, we can observe sites where the effect of the waves contribute to generate alterations which can reach values near to 1 psu. Due to this, it is possible to understand the dominance of the effects of the waves in the distant regions from the entrance of the Patos Lagoon (Points 2, 3 and 5), where the differences present positive values, while at the mouth (Point 1 ) there are negative values demonstrating smaller modulating effect of the waves over the salinity.

Through the temporal series, the points 1, 2, 3 and 4 have shown few significant differences during the time, whereas the points 1 and 5 were chosen for more detailed analysis (Figure 3). Point 1, on the surface and at the bottom, did not present significant differences between salinity being or not affected by the waves, proving that
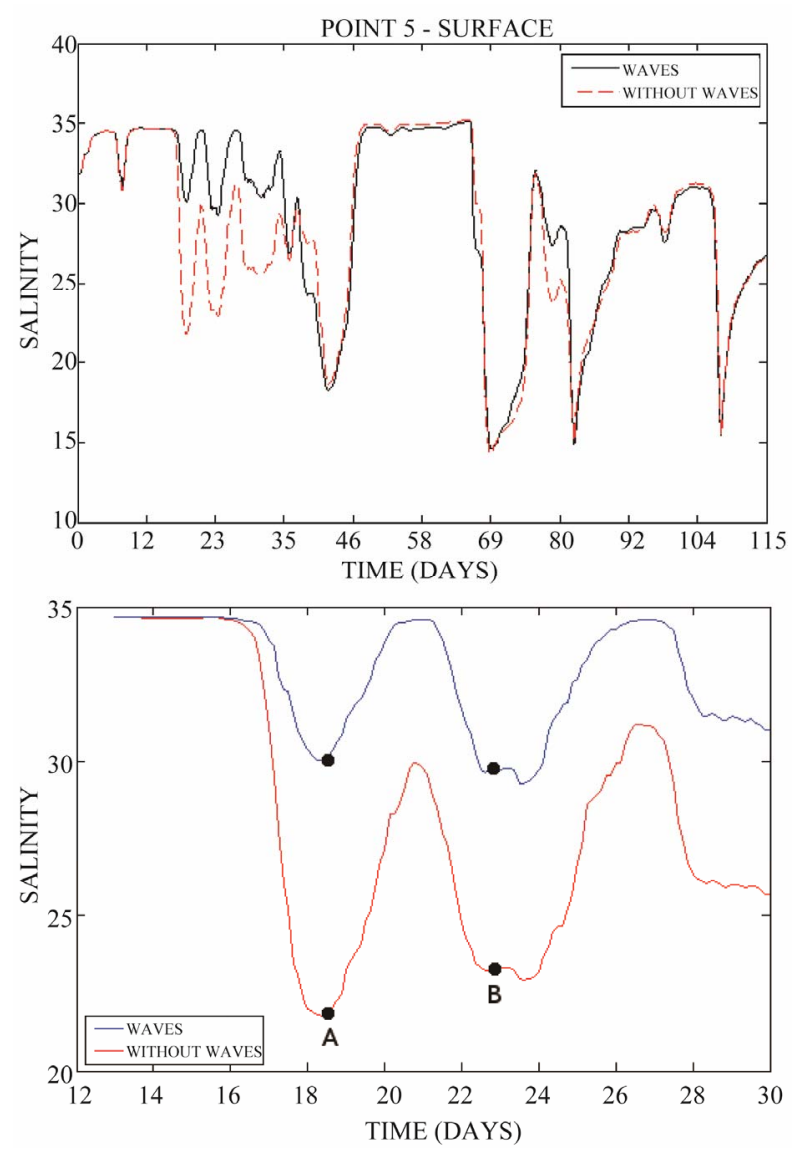

Figure 3. Temporal series of salinity from the surface in the point 5 , and a detail of the interval between the 10th to the 30th days of simulation. The points represent the moment where the vertical profile $A$ (18th) and $B$ (22th) were extracted. 
the wave is not important for mixing processes at the mouth of the Patos Lagoon, hence, only point 5 will be studied.

In point 5 (Figure 3), it is observed, in the temporal series of the superficial salinity, a huge variation during the period from the 10th to the 30th day of simulation (corresponding to the 11th and 31st of January). In this period it was verified the influence of the wave in the mixing of the water column. The sea waves dominate this period $\left(\mathrm{Hs}_{\mathrm{m}}=0.82 \mathrm{~m}, \mathrm{Tp}_{\mathrm{m}}=8.0 \mathrm{~s}, \mathrm{Dp} \mathrm{p}_{\mathrm{m}}=115^{\circ}\right)$ and are able to elevate salinity up to 10 psu on the surface. The predominance of winds from east/northeast enhances the sea formation in the region [20]. According to [20] on the Southern Brazilian Shelf, the typical behavior of the waves occurs predominantly in the direction of peak between $100^{\circ}$ and $160^{\circ}$ (southeast), with heights ranging from 1 to 1.5 , also with periods between 6 and 14 seconds.

From the transects of the period of interest at the point 5 (Figure 4), located $60 \mathrm{~km}$ away from the beginning of the transect of the longitudinal profile, we can analyze the vertical structure of the plume and the effects promoting the mixing generated by the waves. The transects were taken for the interval of interest (days 15 to 28) so that the vertical profiles comparison could be made between the simulations with and without waves.

We understand that the inversions in wind direction generate instability in the center of the plume forcing the plume to be bottom-trapped (Figures 4(a) and (b)), and the opposite occurs when there is a predominance of winds from southeast (Figures 4(c) and (d)), because the plume keeps its fluctuating state allied with a higher spacial influence and also directed to the north. In point 5 , the variations of salinity are dominated due to the presence or absence of the plume in that distance from the coast.

In Figures 4(a) and (b), we can note that the waves influence the transport of the plume in order to reduce its displacement in the north direction, increasing the intrusion of waters with high salinity towards the plume.

Several authors observed that by increasing the plume area, the decrease of the salinity gradient occurs due to radial expansion of the plume ([2,5,21-23]).

In Figures 4(c) and (d), intensification of the winds from the southeast occurs generate velocity disturbances in the layers below the plume, causing the return of the fresh water plume in $5 \mathrm{~km}$, with a subsequently change in the wind direction to the west forcing the fresh water plume to remain bottom-trapped.

During this period, it was noticed that significant wave height tends to increase when the direction of the wind and waves tends to converge, while the inversion of these directions cause the decrease of the significant wave height. This pattern was also seen by [20] and [24].

In all the profiles, it is shown that the salt is advected from the bottom to the surface, so the most superficial layers become more saline.

Towards the open sea, the velocity of the fresh water plume gradually decreases while the plume spreads through the coastal zone. According to [25], the diffusive processes become dominant over the advection and the mix-
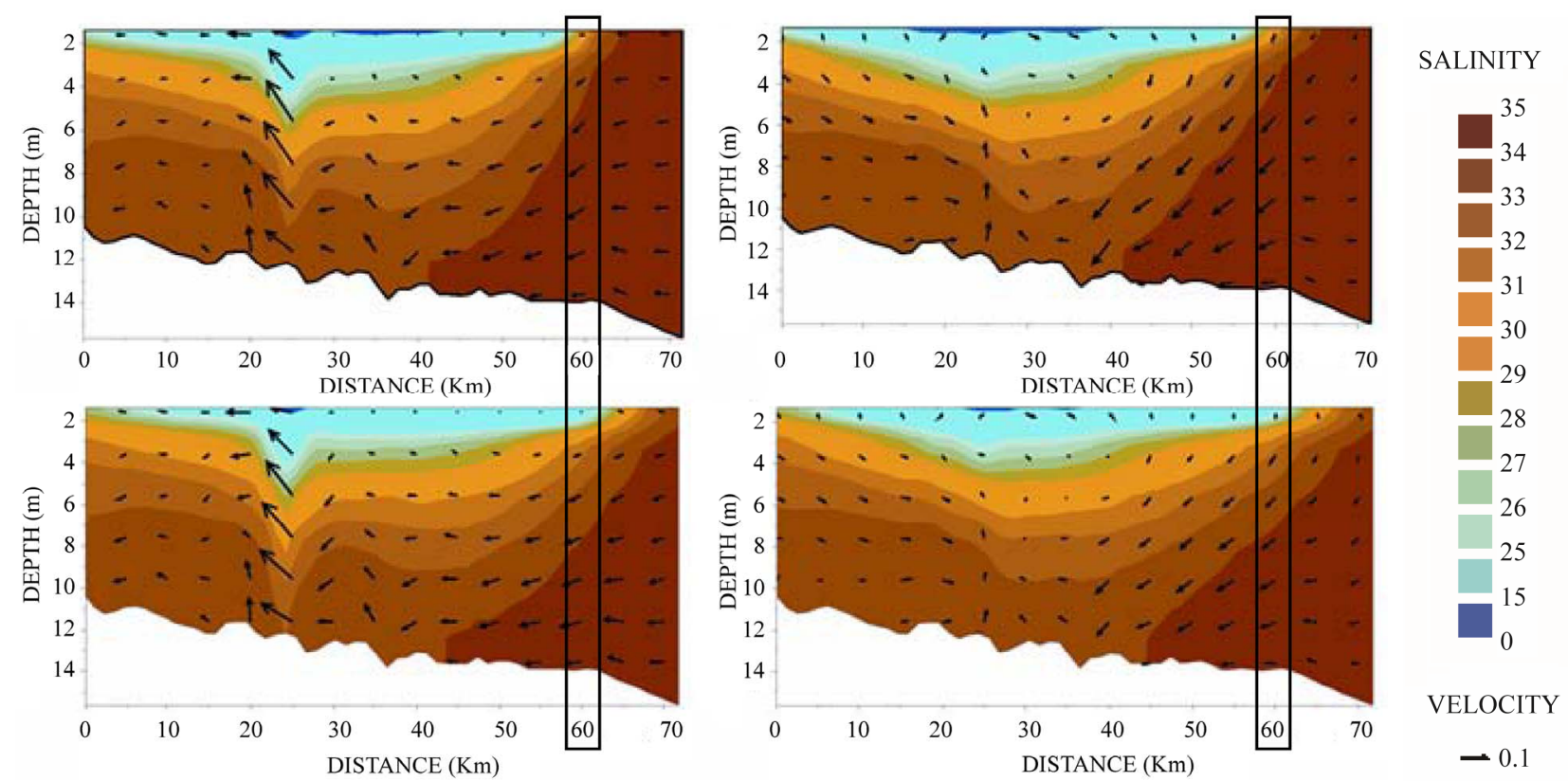

Figure 4. Vertical profiles, longitudinal along the coast. On the upper left (a) the profile with wave on day 18; On the upper right (b) the profile with wave on day 23; On the down left (c) the profile without wave effect on day 18; On the down right (d) the profile without wave effect on day 23. Point 5 is in the distance of $60 \mathrm{~km}$. Vectors show the current velocity (m/s). 
ing processes increase with the vertical scattering of the plume, making the boundary layers of the plume gradually saltier. According to [26], the frontal pressure gradient generated by the meeting of waters of different densities generates a force between drag force and the entrainment, which leads to a vertical circulation that characterizes active estuarine fronts, (as shown in Figure 4), whose meetings of the haline layers with the brackish layers generate strong vertical velocity vectors at the bottom.

Through the Richardson number (Ri), it was possible to demonstrate the effect of the waves on the stratification as a turbulence promoter. Dyer [27] commented that there were many theoretical and laboratory studies on the mechanisms of formation and growth of instabilities inside a stratified interface, and that the transition from laminar to turbulent flow was usually able to occur with Ri $=0.25$. Below this value, the flow becomes unstable, perturbations at the interface take place and there is the break of the layer and the mixture predominates [28].

This analysis validates that mixing processes occur predominantly ( $\mathrm{Ri}<0.25$ ), mainly in the period of days 10 to 30 of the simulation, demonstrating that the action of waves increases the mixture and salinity during this period. Whereas the variation of the Richardson number for the event without waves is smaller, at the same period closer to day 20, where Ri varies from 7 to 1 on the surface, while in 7 meters deep, it varies from 1 to 0.135 , making the relation between [18] and [27] valid, in which $\mathrm{Ri}<0.25$ generates mixture.

This analysis is confirmed by the Brunt-Väisälä frequency (frequency of Buoyancy), demonstrating that in point 5 (Figures 5(a) and (b)) for the interval analyzed there is an elevation in the buoyant period, with superficial changes ranging 0.002 (Figure 5(a)) for 0.83 hours (Figure 5(b)), whereas in $7 \mathrm{~m}$ deep, this elevation can range from 0.83 to 50 hours. Consequently, water layer presented there tends to be less stratified, being rapidly mixed, and this mixing tends to be steadier the more it approaches the bottom.

According to [19], the maximum of the frequency of buoyancy occurs when there is a greater stratification in the water column, as well as the highest perturbations in pycnocline. Relying on this principle, we can conclude that the lowest frequencies of buoyancy occur superficially in the transect in Figure 4 (days 18 and 22). In Figures 5(a) and (b), this fact can be seen as a large decrease in red color on the surface during this period, indicating a reduction in buoyant frequency caused by the waves, which indicates reduction of stratification of the water column, and consequently increase of the mixture in this site.

\section{Conclusions}

The plume of the Patos Lagoon has considerable influence on the haline gradients at the entrance in order to inhibit the mixing provoked by the waves. In point 1 , we conclude that the waves change sensitively the processes of mixing or stratification, this occurs due to the high discharge found in 1998, which makes the water column virtually steady and well stratified, occurring less vertical mixing.

As for a region that receives the effect of the plume less frequently, it is observed a greater influence of waves on the processes of mixing, breaking the layers of stability. This dominant effect of the waves in the region of point 5 occurs with the predominance from the northeast winds and the presence of sea waves which are strong and characterized by having high energy, being able to cause instabilities in layers up to $8 \mathrm{~m}$ deep and elevate surface salinity into $10 \mathrm{psu}$.

It can be concluded from this work:

1) The waves influence on the surface layers in front of the Patos Lagoon jets so that-due to increased rates of mixing - the plume disperses more radially and tends of the Patos Lagoon jets so that-due to increased rates of mixing - the plume disperses more radially and tends

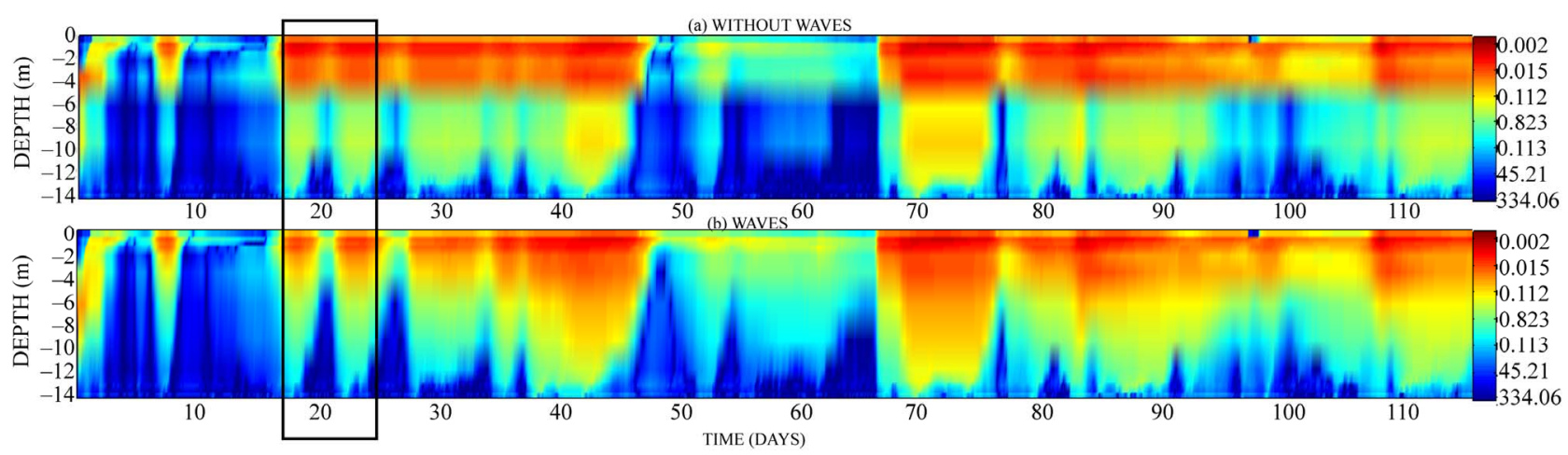

Figura 5. Comparison between the inverse of the Brunt-Väisälä frequency for the simulations with waves (a) and without the waves effects (b). 
to conserve the haline superficial characteristics. The waves perform the greater mixing in the background layers, because their influence in the haline gradients in order to remove the saline intrusion through the bottom;

2) In regions far from the entrance of Patos Lagoon, it is shown that the waves are more effective in the mixing processes, that relies on the fact that the layers remain less stratified, which makes the turbulent processes more effective in this region.

Furthermore, we also observe that, in the north of the entrance of Patos Lagoon, the effect of the waves acts in order to break the instability layers, due to the decreasing reach of the freshwater plume in this region.

3) The mixing parameters studied represent correctly the expected effects for the region, due to the Sea events, demonstrating that the effect of wave action decreases the stratification, decreases the frequency of Brunt-Väisälä and increases the buoyant frequency, and along with the increase the mixing processes.

\section{Acknowledgements}

The authors are grateful to the Fundação de Amparo à Pesquisa do Estado do Rio Grande do Sul (FAPERGS) for sponsoring this research under contract 1018144. Further acknowledgments go to the Brazilian Navy for providing detailed bathymetric data for the coastal area; to the Brazilian National Water Agency and NOAA for supplying the fluvial discharge and wind data sets, respectively; and to HR Wallingford for providing the academic license of the TELEMAC system to accomplish this research.

\section{REFERENCES}

[1] W. C. Marques, E. H. L. Fernandes and O. O. Moller, "Straining and Advection Contributions to the Mixing Process of the Patos Lagoon Coastal Plume, Brazil," Journal of Geophysical Research, Vol. 115, No. C6, 2010, p. 23. doi:10.1029/2009JC005653

[2] W. C. Marques, E. H. L. Fernandes, I. O. Monteiro and O. O. Möller, "Numerical Modeling of the Patos Lagoon Coastal Plume, Brazil," Continental Shelf Research, Vol. 29, No. 3, 2009, pp. 556-571. doi:10.1016/j.csr.2008.09.022

[3] R. H. Stewart, "Introduction to Physical Oceanography," The University of Texas, Austin, 2006.

[4] W. C. Marques, E. H. Fernandes, O. O. Möller Jr., B. C. Moraes and A. Malcherek, "Dynamics of the Patos Lagoon Coastal Plume and Its Contribution to the Deposition Pattern of the Southern Brazilian Inner Shelf,” Journal of Geophysical Research, Vol. 115, No. C10, 2010, p. 22.

[5] D. Burrage, J. Wesson, C. Martinez, T. Pérez, O. O. Möller Jr. and A. Piola, "Patos Lagoon Outflow within the Rio de la Plata Plume Using an Airborne Salinity Mapper : Observing an Embedded Plume,” Continental
Shelf Research, Vol. 28, No. 13, 2008, pp. 1625-1638. doi:10.1016/j.csr.2007.02.014

[6] O. O. Möller Jr. and P. Castaing, "Hydrographical Characteristics of the estuarine area of Patos Lagoon $\left(20^{\circ} \mathrm{S}\right.$, Brazil),” In: G. M. Perillo, M. C. Piccolo and M. Pino Eds., Estuaries of South America: The Geomorphology and Dynamics, Springer Verlag, Berlin, 1999, pp. 83-100. doi:10.1007/978-3-642-60131-6_5

[7] O. O. Möller Jr., J. P. Castello and A. C. Vaz, “The Effect of River Discharge and Winds on the Interannual Variability of the Pink Shrimp Farfantepenaeus Paulensis Production in Patos Lagoon,” Estuaries and Coasts, Vol. 32, No. 4, 2009, pp. 787-796. doi:10.1007/s12237-009-9168-6

[8] E. H. L. Fernandes, K. R. Dyer and O. O. Möller Jr., "Spatial Gradients in the Flow of Southern Patos Lagoon,” Journal of Coastal Research, Vol. 21, No. 4, 2005, pp. 759-769. doi:10.2112/006-NIS.1

[9] V. H. Kourafalou, L. Y. Oey, J. D. Wang and T. N. Lee, "The Fate of River Discharge on the Continental Shelf 1. Modeling the River Plume and the Inner Shelf Coastal current,” Journal of Geophysical Research, Vol. 101, No. C2, 1996, pp. 3415-3434. doi:10.1029/95JC03024

[10] G. P. Barros and W. C. Marques, "Long-Term Temporal Variability of the Freshwater Discharge and Water Levels at Patos Lagoon, Rio Grande do Sul, Brazil,” International Journal of Geophysics, Vol. 2012, 2012, Article ID: 459497, p 11. doi:10.1155/2012/459497

[11] J. M. Hervouet and L. Van Haren, “TELEMAC-2D Principle Note,” Technical Report HE-43/94/051/B, Electricité de France, 1994.

[12] W. C. Marques, E. H. Fernandes, L. A. O. Rocha and A. Malcherek, "Energy Converting Structures in the Southern Brazilian Shelf: Energy Conversion and Its Influence on the Hydrodynamic and Morphodynamic Processes," Journal of Earth Sciences and Geotechnical Engineering, Vol. 1, No. 1, 2012, pp. 61-85.

[13] P. D. Silva, "Interação onda-corrente na Plataforma Continental Interna do Sul do Brasil,” Master Degree Thesis, Instituto de Oceanografia, Universidade Federal de Rio Grande, 2011.

[14] L. A. Wong, J. C. Chen and L. X. Dong, "A Model of the Plume Front of the Pearl River Estuary, China and Adjacent Coast Waters in the Winter Dry Season," Continental Shelf Research, Vol. 24, No. 16, 2004, pp. 1779-1795. doi:10.1016/j.csr.2004.06.007

[15] M. G. Gross, “Oceanography: A View of the Earth," Prentice-Hall, Englewood Cliffs, 1972.

[16] T. R. Akylas, "Nonlinear Forced Wave Phenomena,” In: R. W. Miksad, T. R. Akylas and T. Herbert, Eds., Nonlinear Wave Interactions in Fluids, ASME, New York, 1988, pp. 157-63.

[17] J. M. Hervouet and L. Van Haren, "Recent Advances in Numerical Methods for Fluid Flows,” In: M. G. Anderson, D. E. Walling and P. D. Bates, Eds., Floodplain processes, Wiley, Chichester, 1996, pp. 183-214.

[18] L. B. Miranda, B. M. De Castro and B. Kjerve, "Princípios de Oceanografia Física de Estuários,” Editora da 
Universidade de São Paulo, São Paulo, 2002.

[19] S. Krieger, “Análise de Dados do Projeto COROASLarga Escala,” 2005.

[20] D. C. Cuchiara, E. H. Fernandes, J. C. Strauch, J. C. Winterwerp and L. J. Calliari, "Determination of the Wave Climate for the Southern Brazilian Shelf," Continental Shelf Research, Vol. 29, No. 3, 2009, pp. 545555. doi:10.1016/j.csr.2008.09.025

[21] R. W. Garvine, "Penetration of Buoyant Coastal Discharge onto the Continental Shelf: A Numerical Model Experiment,” Journal of Physical Oceanography, Vol. 29, No. 8, 1999, pp. 1892-1909.

doi:10.1175/1520-0485(1999)029<1892:POBCDO >2.0.C $\underline{\mathrm{O} ; 2}$

[22] S.-Y. Chao, "Tidal Modulation of Estuarine Plumes," Journal of Physical Oceanography, Vol. 20, No. 7, 1990, pp. 1115-1123.

[23] X. Guo and A. Valle-Levinson, "Tidal Effects on Estu- arine Circulation and Outflow Plume in the Chesapeake Bay,” Continental Shelf Research, Vol. 27, No. 1, 2007, pp. 20-42.

[24] I. S. Robinson, “Satellite Oceanography,” Ellis Horwood Limited, Chichester, 1985.

[25] K. R. Dyer, "Circulation and Mixing in Stratified Estuaries," Marine Chemistry, Vol. 32, No. 2-4, 1991, pp. 111120. doi:10.1016/0304-4203(91)90031-Q

[26] R. W. Garvine, "Observations of the Motion Field of the Connecticut River plume," Journal of Geophysical Research, Vol. 82, No. 3, 1977, pp. 441-454. doi:10.1029/JC082i003p00441

[27] K. R. Dyer, “Estuaries,” John Wiley \& Sons, Hoboken, 1997.

[28] K. R. Dyer and A. L. New, "Intermittency in Estuarine Mixing,” In: D. A. Wolfe, Ed., Estuarine Variability, Harcourt Brace Jovanovich, Orlando, 1986, pp. 321-339. 